(Abelev, 1971; Ruoslahti et al., 1973). We have seen two cases of hepatic coma, caused by an acute hepatitis, in which $\alpha$-fetoprotein levels were 150 and $350 \mathrm{ng} / \mathrm{ml}$ respectively, and the two cases of coma in the present study had levels of 525 and $4,000 \mathrm{ng} / \mathrm{ml}$ respectively. It may be significant that the patient with the highest level was the only one who recovered. More extensive studies will be needed to establish the consistency and possible diagnostic significance of a correlation between the extent of the regenerative response and the $\alpha$-fetoprotein level in man.

\section{References}

Abelev, G. I. (1971). Advances in Cancer Research, 14, 295.
Abelev, G. I., et al. (1971). Byulleten' Eksperimental'noi Biologii i Mediciny,

Akai, 3., and Kato, K. (1973). Gann Monograph of Cancer Research, 14, 149. Bakirov, R. D. (1968). Byulleten' Eksperimental'noi Biologii i Mediciny, 2, 45. Chayvialle, J. A. P., and Ganguli, P. C. (1973). Lancet, 1, 1355.

Elgort, D. A., Abelev, G. I., and O'Connor, G. T. (1972). International fo: D. Anal of Cancer, 10, 331.

Nishi, S., and Hirai, H. (1973). Gann Monograph of Cancer Research, 14, 79.

Ruoslahti, E., and Seppälä, M. (1971). International fournal of Cancer, 8, 374.

Ruoslahti, E., and Seppälä, M. (1971). International fournal of Cancer, 8, 374 Ruoslahti, E., and Seppälä, M. (1972). Lancet, 2, 278.

Ruoslahti, E., Seppälä, M., Vuopio, P., Saksela, E., and Peltokallio, P. (1972). Fournal of the National Cancer Institute, 49, 623.

Ruoslahti, E., Seppälä, M., Räsänen, J., Vuopio, P., and Helske, T. (1973). Scandinavian Journal of Gastroenterology, 8, 197.

Ruoslahti, E., et al. (1974). Proceedings of $7 t h$ Miles Symposium. Baltimore,
Md. In press. Seppälä, M., and Ruoslahti, E. (1972). Lancet, 1, 375.

\title{
The Kidney and Intravascular Coagulation in Myelomatosis
}

\author{
A. MILFORD WARD, F. E. PRESTON
}

British Medical fournal, 1974, 2, 529-531

\section{Summary}

In 15 out of 35 patients with myelomatosis histological examination showed intravascular fibrin within the glomeruli, and this was associated with proliferation of the mesangial complex in 12. The presence of intravascular fibrin and mesangial proliferation was not associated with any specific immunoglobulin abnormality or with the presence or absence of Bence Jones proteinuria. In addition to fibrin being present within glomerular capillaries it was also shown in intertubular capillaries in three cases of myelomatosis with acute tubular necrosis. It is suggested that intraglomerular coagulation and fibrin deposition may contribute to the genesis of renal failure in myelomatosis.

\section{Introduction}

Renal failure is a common complication and a not infrequent cause of death in myelomatosis (Medical Research Council, 1973), there being a continuous spectrum of changes from minimal functional impairment to acute oliguric failure. The currently accepted causes of renal failure in myelomatosis include hypercalcaemia, pyelonephritis, "myeloma kidney," and amyloidosis (Hobbs, 1971). Hobbs has also shown that whereas the proportion of myelomatosis deaths due to renal failure used to exceed $30 \%$ modern cytotoxic therapy has reduced this to $15 \%$, but $10 \%$ still present with irreversible renal failure and die within the first two months of therapy. A high blood urea at the time of initial presentation is a grave prognostic sign (Peto, 1971). Other reponts have suggested that some patients with myelomatosis develop coagulation anomalies (Vigliano and Horowitz, 1967), abnormalities of fibrin polymerization (Lackner et al., 1970), and a hypercoagulable state as shown by an increased incidence of thromboembolism (Catovsky et al., 1970) and by diminished fibrinolysis (Preston and Lee, 1972). In the light of these con\footnotetext{
Department of Immunology, The Medical School, Hallamshire
Hospital, Sheffield S10 $2 \mathrm{R}$.

A. MILFORD WARD, M.B., M.R.C.PATH., Senior Lecturer and Honorary Consultant

University Department of Haematology, Royal Infirmary, Sheffield S6 3DA

F. E. PRESTON, M.D., M.R.C.PATH., Consultant Haematologist
}

siderations and in view of the increasing incidence of fibrin in the pathogenesis of the glomerulopathies and awareness of the importance of this fact (Clarkson et al., 1971) the possible role of fibrin in the genesis of the renal lesion in myelomatosis was investigated initially by a retrospective light and immunofluorescent microscopical study.

\section{Methods}

Renal tissue was obtained by percutaneous needle biopsy in three cases and at necropsy from a further 32 cases of myelomatosis. Control tissues were obtained at necropsy from five patients with no evidence of myelomatosis or renal disease. Tissue for light microscopy was fixed in $10 \%$ formol saline, and $5-\mu \mathrm{m}$ sections embedded in paraffin were stained with haematoxylin and eosin, Martius scarlet blue, periodic-acid Schiff, periodic-acid silver methamamine, Sirius red, and picro-Mallory. When available a further sample of tissue was snap-frozen and $3-\mu \mathrm{m}$ cryostat sections cut for immunofluorescent examination. These sections were examined by direct immunofluorescence, using F.I.T.C. conjugated rabbit antisera specific for human fibrin and fibrinogen, kappa and lambda immunoglobulin light chains, and IgG, IgA, IgM, and IgD heavy chains. The immunological specificity of the staining was tested by the "blocking effect" of pretreatment with unlabelled antibody.

The case records were reviewed and biochemical, haematological, and immunochemical data correlated with the histological findings.

\section{Results}

\section{LIGHT MICROSCOPY}

In eight out of the 35 cases light microscopy showed evidence of metastatic calcification either in the epithelium of tubular cells or in the interstitium, 13 cases showed evidence of pyelonephritis, and 12 cases showed the classical appearances of "myeloma kidney" with laminated casts and epithelial syncytia in the distal tubules. Only two cases showed stainable amyloid. The glomeruli showed evidence of mesangial proliferation in 16 cases, though there was no evidence of epithelial or juxtaglomerular proliferation. Fifteen cases showed fibrin deposition on the endothelium of the glomerular capillaries, three cases also showing occulsion of intertubular capillaries by fibrin thrombi and acute tubular necrosis 
Laboratory Findings in 35 Myleomatosis Patients with and without Microthrombi in Glomerular Capillaries

\begin{tabular}{|c|c|c|c|c|c|c|c|c|c|}
\hline \multirow{2}{*}{ Case No. } & \multirow{2}{*}{ Sex and Age } & \multirow{2}{*}{$\begin{array}{c}\text { Monoclonal } \\
\text { Ig } \\
\text { Type } \\
\end{array}$} & \multirow{2}{*}{$\begin{array}{c}\text { Bence Jones } \\
\text { Proteinuria } \\
\text { (mg/100 ml) }\end{array}$} & \multirow{2}{*}{ Urea $\mathrm{mg} / 100 \mathrm{ml}$} & \multirow{2}{*}{$\begin{array}{c}\text { Mesangial } \\
\text { Proliferation }\end{array}$} & \multicolumn{2}{|c|}{$\begin{array}{l}\text { Intraglomerular } \\
\text { Fibrin }\end{array}$} & \multirow{2}{*}{$\begin{array}{c}\text { Intertubular } \\
\text { Vessel } \\
\text { Occlusion }\end{array}$} & \multirow{2}{*}{$\begin{array}{c}\text { Extrarenal } \\
\text { Large Vesse } \\
\text { Occlusion }\end{array}$} \\
\hline & & & & & & M.S.B. & I.F. & & \\
\hline \multicolumn{10}{|c|}{ Patients with Microthrombi in Glomerular Capillaries } \\
\hline $\begin{array}{r}1 \\
2 \\
3 \\
4 \\
5 \\
6 \\
7 \\
8 \\
9 \\
10 \\
11 \\
12 \\
13 \\
14 \\
15\end{array}$ & $\begin{array}{ll}\text { M. } & 59 \\
\text { M. } & 80 \\
\text { M. } & 69 \\
\text { M. } & 64 \\
\text { M. } & 42 \\
\text { M. } & 79 \\
\text { M. } & 65 \\
\text { F. } & 57 \\
\text { M. } & 58 \\
\text { F. } & 76 \\
\text { F. } & 82 \\
\text { M. } & 41 \\
\text { M. } & 49 \\
\text { M. } & 76 \\
\text { M. } & 60\end{array}$ & 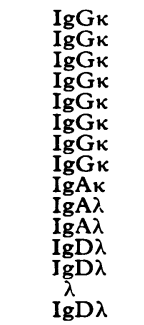 & $\begin{array}{l}1-99 \\
1-99 \\
1-99 \\
1-99 \\
<1 \\
<1 \\
1-99 \\
1-99 \\
<1 \\
1-99 \\
1-99 \\
>100 \\
>100 \\
>100 \\
>100\end{array}$ & \begin{tabular}{|r|}
260 \\
32 \\
50 \\
154 \\
70 \\
450 \\
450 \\
265 \\
78 \\
N.D. \\
77 \\
140 \\
36 \\
115 \\
62
\end{tabular} & $\begin{array}{l}- \\
+ \\
+ \\
+ \\
+ \\
+ \\
+ \\
+ \\
+ \\
+ \\
+ \\
+ \\
+\end{array}$ & $\begin{array}{l}\text { E. } \\
\text { E. } \\
\text { E. } \\
\text { E. } \\
\text { E. } \\
\text { E. } \\
\text { E. } \\
\text { E. } \\
\text { E. } \\
\text { E. } \\
\text { E. } \\
\text { E. } \\
\text { E. } \\
\text { E. } \\
\text { E. }\end{array}$ & $\begin{array}{l}\text { E. } \\
\text { E. } \\
\text { E.M. } \\
\text { E. } \\
\text { E. } \\
\text { N.D. } \\
\text { E.M. } \\
\text { N.D. } \\
\text { E. } \\
\text { E. } \\
\text { E. M. } \\
\text { N.D. } \\
\text { N.D. } \\
\text { E. M. } \\
\text { N.D. }\end{array}$ & $\begin{array}{l} \pm \\
= \\
= \\
= \\
\overline{+} \\
\pm \\
= \\
= \\
= \\
=\end{array}$ & $\begin{array}{l} \pm \\
= \\
= \\
= \\
= \\
+ \\
+ \\
\pm \\
= \\
=\end{array}$ \\
\hline \multicolumn{10}{|c|}{ Patients without Microthrombi in G lomerular Capillaries } \\
\hline $\begin{array}{l}16 \\
17 \\
18 \\
19 \\
20 \\
21 \\
22 \\
23 \\
24 \\
35 \\
26 \\
27 \\
28 \\
29 \\
30 \\
31 \\
32 \\
33 \\
34 \\
35\end{array}$ & $\begin{array}{ll}M . & 62 \\
\text { F. } & 67 \\
\text { M. } & 75 \\
\text { F. } & 57 \\
\text { F. } & 50 \\
F . & 78 \\
\text { F. } & 74 \\
\text { F. } & 69 \\
\text { M. } & 49 \\
\text { F. } & 51 \\
\text { F. } & 72 \\
\text { M. } & 48 \\
\text { F. } & 64 \\
\text { F. } & 69 \\
\text { F. } & 45 \\
\text { M. } & 54 \\
\text { M. } & 53 \\
\text { M. } & 49 \\
\text { M. } & 58 \\
\text { M. } & 66\end{array}$ & 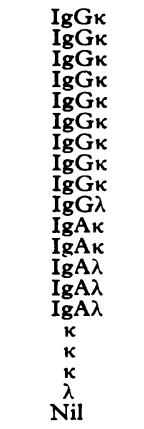 & $\begin{array}{l}<1 \\
<1 \\
<1 \\
1-99 \\
1-99 \\
<1 \\
<1 \\
1-99 \\
1-99 \\
<1 \\
<1 \\
1-99 \\
<1 \\
<1 \\
1-99 \\
>100 \\
>100 \\
>100 \\
>100 \\
<1\end{array}$ & \begin{tabular}{|c|}
388 \\
150 \\
81 \\
80 \\
154 \\
N.D. \\
N.D. \\
N.D. \\
N.D. \\
44 \\
50 \\
N.D. \\
N.D. \\
164 \\
48 \\
24 \\
167 \\
N.D. \\
118 \\
92
\end{tabular} & $\begin{array}{l}\overline{-} \\
\pm \\
\bar{z} \\
\pm \\
= \\
\overline{+} \\
+ \\
\pm \\
= \\
= \\
= \\
= \\
= \\
=\end{array}$ & $\begin{array}{l}= \\
= \\
= \\
= \\
= \\
= \\
= \\
= \\
= \\
= \\
= \\
= \\
= \\
=\end{array}$ & $\begin{array}{l}\text { N.D. } \\
\text { N.D. } \\
\text { N.D. } \\
\text { N.D. } \\
\text { N.D. } \\
\text { N.D. } \\
\text { N.D. } \\
\text { N.D. } \\
\text { N.D. } \\
\text { N.D. } \\
\text { N.D. } \\
\text { N.D. } \\
\text { N.D. } \\
\text { N.D. } \\
\text { N.D. } \\
\text { N.D. } \\
\text { N.D. }\end{array}$ & $\begin{array}{l}= \\
= \\
= \\
= \\
= \\
= \\
= \\
= \\
= \\
= \\
= \\
= \\
=\end{array}$ & $\begin{array}{l}\bar{z} \\
\pm \\
= \\
= \\
= \\
= \\
= \\
= \\
= \\
= \\
= \\
= \\
= \\
=\end{array}$ \\
\hline
\end{tabular}

N.D. = Not done

M.S.B. = Martius scarlet blue.

I.F. = Immunofluorescence.

$\mathrm{E} .=$ Endothelial and luminal deposits of fibrin

M. = Granular mesangial deposits of fibrin.

(cases 1, 8, and 9). The necropsy showed large vessel occlusion in five cases, four with glomerular fibrin deposition and one without (see table).

\section{IMMUNOFLUORESCENT MICROSCOPY}

Tissue was available for immunofluorescent microscopical examination in 13 cases. In 10 of these there was extensive granular or beaded deposition of fibrin along the endothelium of the glomerular capillaries together with focal luminal occlusion and in four cases $(3,7,11$, and 14) additional granular deposits were seen in the mesangial complex (see table). There was no evidence of epimembranous or endomembranous deposition of fibrin and no extraglomerular deposition of fibrin save in the intertubular capillaries (cases 1 and 9). Staining with immunoglobulin heavy and light chain specific antisera showed all components to be present within the tubular casts though the intensity of fluorescence favoured the heavy and light chain type of the monoclonal component. Reabsorption droplets of Bence Jones protein within tubular cells stained strongly with the appropriate light chain specific antisera.

\section{Discussion}

Within recent years much attention has been focussed on the role of intraglomerular fibrin in the pathogenesis of various renal disorders (Clarkson et al., 1971). Intraglomerular coagulation undoubtedly occurs in patients with certain renal disorders, but it has not been completely resolved whether renal damage predisposes to deposition of fibrin or whether deposited fibrin induces secondary renal damage. Clarkson et al. (1970) showed fibrin in the renal glomeruli and peritubular capillaries in acute tubular necrosis, a condition in which the glomeruli are usually considered to be normal. They proposed that the fibrin impaired glomerular filtration and thus induced the oliguria seen in this condition. Intravascular deposition of fibrin may reflect increased activation of the coagulation mechanism with an inadequate fibrinolytic response, or it may be due to impairment of the normal fibrinolytic mechanisms. Preston and Lee (1972) observed impairment of the fibrinolytic mechanisms in 10 out of 12 patients with myelomatosis, and they considered that this abnormality could, at least pantially, be responsible for the increased incidence of thromboembolism in myelomatosis (Catovsky et al., 1970).

In our retrospective series we observed intraglomerular fibrin in 15 of the 35 patients available for study. Endothelial and luminal deposits of fibrin were present in each of the 15 patients, and in four cases there was additional deposition of fibrin within the mesangial complex. Occlusion of intertubular or peritubular capillaries was observed in three of the 15 patients, and large-vessel occlusion was present in four. Though there was good correlation between the presence of fibrin and mesangial proliferation endothelial and epithelial proliferation was not seen. There was no obvious correlation between the presence of intraglomerular fibrin and Bence Jones proteinuria. Similarly there was no correlation between the degree of increase of the blood urea and the presence of intraglomerular fibrin.

These observations would seem to argue against the possibility that the deposition of fibrin occurs as a result of preexisting renal damage, and they suggest that the deposition is of some aetiological importance in the genesis of the renal lesion in myelomatosis. Further work is in progress in an attempt to define the importance of these findings.

We gratefully acknowledge support from the Committee of Cancer Research, University of Sheffield (Yorkshire Cancer Campaign), Grant No. 4034/02. 
References

Catovsky, D., Ikoku, N. B., Pitney, W. R., and Galton, D. A. G. (1970). British Medical fournal, 3, 438 .

Clarkson, A. R., MacDonald, M. K., Fuster, V., Cash, J. D., and Robson, J. S. (1970). Quarterly fournal of Medicine, 39, 585 .

Clarkson, A. R., MacDonald, M. K., Petrie, J. J. B., Cash, J. D., Robson, J. S. (1971). British Medical fournal, 3, 447.
Hobbs, J. R., (1971). Personal communication.

Lackner, H., Hunt, V., Zucker, M. B., and Pearson, J. (1970). British Fournal of Haematology, 18, 625

Medical Research Council. (1973). British fournal of Haematology, 24, 123.

Peto, R. (1971). British Medical fournal, 2, 324.

Preston, F. E., and Lee D. (1972). Acta Haematologica, 47, 65.

Vigliano, E. M., and Horowitz, H. I. (1967). Blood, 29, 823.

\title{
Trophic Skin Ulceration of Leprosy: Skin and Serum Zinc Concentrations
}

\author{
BENG BEE OON, KIT YEW KHONG, MALCOLM W. GREAVES, VALERIE M. PLUMMER
}

British Medical fournal, 1974, 2, 531-533

\section{Summary}

Skin and serum zinc measurements have been made in patients with leprosy with and without trophic skin ulceration and in several other groups. Serum zinc concentrations were decreased in leprosy irrespective of the presence or absence of skin ulceration. Serum zinc concentrations in leprosy were also unrelated to smears positive for Mycobacterium leprae and to the clinical type of leprosy. Since a decrease of the serum zinc was also found in patients with dermatitis herpetiformis and pulmonary tuberculosis it seems likely that the decreased serum zinc in leprosy is a nonspecific metabolic consequence of chronic skin and internal disease. The mean skin zinc concentration in leprosy did not differ significantly from the corresponding value in control subjects, the lack of agreement between serum and skin concentrations being possibly related to the presence of nonexchangeable keratin-bound zinc in skin. Though the clinical significance of lowered serum zinc concentrations in leprosy is uncertain therapeutic trials of zinc treatment in leprosy with trophic skin ulceration seem justifiable.

\section{Introduction}

The association between chronic skin ulceration from different causes and lowered plasma or serum zinc concentrations has been shown in several studies (Greaves and Boyde, 1967; Withers et al., 1968; Halstead and Smith, 1970; Serjeant et al., 1970; Hallbook and Lanner, 1972). There is also evidence that supplementation of dietary zinc may promate the healing of ulcers in patients with low plasma or serum zinc concentrations (Husain, 1969; Serjeant et al., 1970; Hallbook and Lanner, 1972). In leprosy chronic indolent plantar or trophic ulceration is a common cause of disability. We have therefore investigated skin and serum zinc concentrations in patients with leprosy and skin ulceration and in several control groups.

Trafalgar Home, Yio Chu Kang Road, Singapore BENG BEE OON, M.B., M.R.C.P., Medical Superintendent KIT YEW KHONG, L.M.S.S.A., Medical Officer

University Department of Dermatology, Royal Victoria Infirmary, Newcastle upon Tyne NE1 4LP

MALCOLM W. GREAVES, M.D., M.R.C.P., Reader in Dermatology

VALERIE M. PLUMMER, Research Technician

\section{Patients and Methods}

Altogether 93 subjects were studied. Of these, 39 were leprosy inpatients, 21 aged 27-74 years with chronic skin ulceration (five of whom gave smears positive for Mycobacterium leprae) and 18 aged 20-68 years with no ulceration (11 of whom gave smears positive for $M$. leprae); 16 aged 19-71 years were inpatients with ohronic pulmonary tuberculosis receiving chemotherapy; 33 aged 17-74 years were attending hospital as outpatients with minor genitourinary and skin ailments (these patients serving as healthy controls); and 5 aged 34-65 years with dermatitis herpetiformis were outpatients receiving 100$200 \mathrm{mg}$ dapsone daily. All the leprosy patients were on dapsone treatment at the Trafalgar Home Leprosarium, Singapore. The inpatient groups were receiving similar diets which were nutritionally adequate. Fully informed consent for the investigation was obtained from all the patients.

For the skin zinc determinations six 4-mm full-thickness punch biopsy specimens were removed from the upper and outer aspect of the thigh using a stainless steel, electrically driven, high-speed rotary drill (Shuster and Bottoms, 1963). This procedure is almost painless and obviates the need for local anaesthesia. Great care was taken not to overstretch the skin. The specimens were stored in a sealed polyethylene tube before analysis. A digest of the six specimens was prepared by the method of Harrison et al. (1968). The specimens were rinsed in $10 \%$ formaldehyde (reagent grade, zinc free) to remove any blood contamination, oven-dried overnight, weighed and transferred to a volumetric flask for digestion. Wet digestion was then carried out using nitric acid and perchloric acid (Hopkins and Williams Ltd., atomic absorption grade). The volume of the final digest was $1.6 \mathrm{ml}$. Digests were diluted to $20 \mathrm{ml}$ with deionized water before analysis of the zinc concentration. To prevent zinc contamination during handling of the skin samples and digests stainless steel instruments were used to transfer the specimens to the zinc-free polyethylene containers and all glassware was rendered zinc-free by soaking overnight in ethylenediamine tetra-acetic acid and rinsing in deionized water.

Zinc analysis was carried out using a Unicam SP 1950 atomic absorption spectrophotometer with an air-acetylene flame. The multi-slot burner was coated with plastic to prevent acid corrosion. Standand curves $(5,10,25$, and $50 \mu \mathrm{g} /$ $100 \mathrm{ml}$ ) were obtained by using a standard zinc solution (1 $\mathrm{mg} / \mathrm{ml}$, B.D.H.) diluted with deionized water. A direct concentration readout was used. Reproducible readings were obtained from solutions containing less than $10 \mu \mathrm{g} \mathrm{zinc} / 100 \mathrm{ml}$. Reagent blanks were unrecordable. Results expressed in terms of dry weight of skin may be unsatisfactory since though the zinc content of the skin is mainly epidermal (Molokhia and Pontnoy, 1969) dermal thickness varies greatly between individuals. Results were therefore also calculated in terms of 